\title{
Las epidemias en La Pampa (Argentina), en perspectiva histórica*
}

\author{
The epidemics in La Pampa (Argentina), \\ from a historical perspective
}

\section{María Silvia Di Liscia ${ }^{i}$ \\ ' Instituto de Estudios Históricos y Sociales de La Pampa/Universidad Nacional de La Pampa. Santa Rosa - La Pampa - Argentina orcid.org/0000-0002-0555-0285 silviadiliscia@gmail.com}

Recebido em 21 ago. 2020. Aprovado em 28 set. 2020.
DI LISCIA, María Silvia. Las epidemias en La Pampa (Argentina), en perspectiva histórica. História, Ciências, Saúde - Manguinhos, Rio de Janeiro, v.28, n.3, jul.-set. 2021, p.869-874.

\section{Resumen}

Este artículo describe el inicio de las preocupaciones sanitarias vinculadas a las epidemias ocurridas durante el siglo XX en La Pampa, provincia argentina. Las epidemias, como las de la viruela, fueron un estímulo para estas políticas que frecuentemente tuvieron origen en Buenos Aires, la capital del país. El contagio de muchas epidemias dependía de carencias de infraestructura: agua, desagüe y desecho adecuado de basuras, de la ausencia de un número suficiente de trabajadores de salud, de la presencia de vectores transmisores de enfermedades como los mosquitos y, en última instancia, de la pobreza. La experiencia histórica descrita en este texto resalta la importancia de analizar el impacto del SARS-CoV-2 más allá de las grandes ciudades.

Palabras clave: Argentina; historia; epidemias; La Pampa; viruela.

\begin{abstract}
This article describes the emergence of health concerns relating to the epidemics that occurred during the twentieth century in La Pampa, a province in Argentina. Epidemics such as smallpox drove such policies, which frequently originated in Buenos Aires, the country's capital. The spread of many epidemics was due to shortages: water, sewage and adequate refuse disposal, an insufficient number of health care workers, the presence of disease transmission vectors such as mosquitos, and, ultimately, poverty. The historical experience described in this text highlights the importance of analyzing the impact of SARS-CoV-2 beyond the big cities.
\end{abstract}

Keywords: Argentina; history; epidemics; La Pampa; smallpox. 
P or primera vez en su corta historia, la provincia de La Pampa (Argentina) ha declarado una cuarentena epidémica. En esta provincia, ubicada en el centro del país, un virus de alto contagio denominado SARS-CoV-2 impuso en marzo de 2020 el aislamiento y confinación a la totalidad de la población para salvaguardar la salud. A la vez, la cuarentena afecta y afectará las actividades económicas, las relaciones sociales e interpersonales y las instituciones públicas y privadas en niveles y aspectos que aún no podemos evaluar.

Una de las primeras epidemias de las que tenemos noticias en La Pampa avanzó con el Ejército nacional comandado por Julio A. Roca, cuando el gobierno conservador de entonces conquistó las tierras de pueblos originarios. Las tropas del Ejército dispersaron, quizás no intencionalmente, el virus de la viruela entre la población indígena, con quien había escaso o nulo contacto y a quien se puede definir como virgin soil (suelo virgen). Los "indios de lanza", sus mujeres y niños no fueron solo vencidos por las armas, sino que el impacto de la epidemia fue fatal, tanto en vidas humanas como en su cohesión social y creencias, afectando así sus capacidades bélicas. Estos varones, mujeres y niños, pertenecientes a diferentes etnias de La Pampa y La Patagonia, capturados luego de la expedición militar de Roca, eran conducidos a la Isla Martín García, lugar utilizado como lazareto y cárcel. Luego, la mayoría de las mujeres y niños se repartieron entre las familias y el resto fue reunido por sacerdotes salesianos en distintas misiones, incorporados al Ejército, como ya lo había sido otro núcleo de indígenas antes de la campaña o bien retornaron a las tierras otorgadas por el gobierno nacional. Pero muchos murieron víctimas, sobre todo, de la viruela que ya había aparecido como epidemia en los campamentos militares y que los mismos indígenas acarrearon a la prisión isleña y luego a Buenos Aires.

La viruela era - y digo en pasado porque se trata de la primera enfermedad erradicada formalmente por la Organización Mundial de la Salud en 1980 - una peligrosa enfermedad, afectaba por igual a adultos e infantes y sus pústulas dejaban en los supervivientes una marca indeleble en la piel. También se trató de una de las primeras experiencias exitosas de prevención; primero la inoculación y luego la vacuna antivariólica podían evitarla con cierta eficacia. Los médicos de entonces sabían de su éxito y la recomendaban a sus pacientes, muchos renuentes a vacunarse.

En la epidemia indicada, que afectaba a grupos no inmunizados y podía extenderse a otros, destacados médicos evidenciaron que los contingentes de indios no habían sido vacunados, a sabiendas del resultado nefasto para ellos y el resto de la población "blanca". En 1879 habían ingresado al Hospital San Roque de Buenos Aires 171 mujeres variolosas, de las cuales ochenta eran indias y la mortandad fue del 38,8\% en las indígenas y solo al $11 \%$ en el resto. Dos célebres higienistas que trabajaban en lazaretos y hospitales de la capital argentina denunciaron que no se había inmunizado convenientemente a la población cautiva. Emilio Coni y José Penna, luego director del Departamento Nacional de Higiene, criticaron acerbamente la negligencia de ciertos militares ya que era conocida la susceptibilidad y gravedad de la enfermedad en aquellos grupos étnicos aislados, cuestión que se acerca en parte a las teorías actuales (Di Liscia, 2011).

Una cuestión importante a recordar: esta epidemia sirvió de ejemplo para que se aprobara en la legislatura bonaerense la obligatoriedad de la vacunación antivariólica en 1886; creemos que tanto la epidemia como la insistencia de varios de los higienistas antes citados 
fueron elementos clave que terminaron con las dudas que existían sobre la inmunización de la población, como ha sucedido (y quizás sucederá) en otras historias de las enfermedades.

Si nos remontamos a la Argentina de finales del siglo XIX, la expansión de la fiebre amarilla, la peste, la viruela, el tifus, el cólera y muchas otras enfermedades eran un llamado de alerta para los sectores dirigentes del entorno conservador, a quienes preocupaba tanto el aumento de la mortalidad como el descenso de la actividad económica. Apoyados sobre todo por médicos, proclamaron la necesidad de higienizar las ciudades y las costumbres de sus habitantes, fueran estos criollos o migrantes. No era ésta solamente una preocupación humanitaria. En las populosas urbes del litoral argentino, las epidemias pusieron a la enfermedad como parte central de la agenda política y se enhebraron con la "cuestión social" y el progreso. El país debía librarse de virus y bacterias que periódicamente barrían a la población trabajadora y adulta para ser parte del concierto de las naciones modernas y civilizadas.

Pero, ¿todas las ciudades argentinas tuvieron similar preocupación higiénica? Recordemos que el contagio de muchas epidemias dependía, y depende, de carencias (agua potable), de vectores (mosquitos, piojos y ratas), de la abundancia de basuras y detritus y finalmente, de la pobreza y escasez de recursos. En Buenos Aires, Rosario y Córdoba, las viviendas insalubres y míseras surgían a medida que se expandían las ciudades en terrenos bajos e inundables y en los conventillos se hacinaban familias enteras. Las epidemias, por lo tanto, hacían emerger un conjunto social casi invisible, pero, a la vez, necesario para multitud de tareas y cuya salud evitaba la infección de los más prósperos.

En gran parte del país, sin embargo, éstas no eran las principales preocupaciones. En los diez territorios nacionales - vacíos de población en el imaginario positivista de entonces que desconocía los derechos de las poblaciones originarias - las campañas militares habían tenido como correlato la ampliación de la frontera agrícola ganadera. En el de La Pampa, hacia 1884, miles de migrantes europeos y de otras provincias se instalaron en el campo y formaron pequeños centros urbanos. Cuatro años después, se presentó una epidemia de cólera, que no se extendió seguramente porque la población estaba disgregada y el contagio se produce sobre todo a través del consumo de agua contaminada con las heces de los enfermos. Años después, la densidad del territorio seguía siendo baja: en 1914 alcanzaba a $0,7 \mathrm{hab} / \mathrm{km}^{2}$ mientras que la media del total del país era $2,8 \mathrm{hab} / \mathrm{km}^{2}$.

Hasta la década de 1930, los gobernadores territoriales no reconocieron la salud como un problema social. En estos vastos espacios la preocupación mayor era gestionar una administración escasa y escuelas insuficientes, $u$ obtener caballos y armas para la policía, que veía circular a vagabundos y bandidos sin poderlos contenerlos. El orden y la instrucción fueron los ejes de estas primeras instancias de gobiernos con muy bajo presupuesto, que debían fomentar el crecimiento de la población y con ello la instalación de comercios y empresas en todo el territorio. En los informes anuales, los funcionarios, nombrados por el presidente, indicaron las capacidades productivas reales y potenciales de La Pampa, su población trabajadora y el clima salutífero, que expulsaba las epidemias con sus fuertes vientos. La información estadística les daba la razón en la escasez de enfermos; uno de los más formidables instrumentos censales, el de 1914, ni siquiera consideraba a los territorios nacionales en esa valoración, y cuando lo hacía, el recuento 
era insignificante, asegurando que la población de esas "nuevas áreas" era joven y sana, carente de infecciones.

Las primeras políticas sanitarias de las que tenemos noticias provinieron del ámbito nacional. El territorio o gobernación de La Pampa, como el resto de los territorios, dependió de las directivas sanitarias del Departamento Nacional de Higiene. Desde 1884 hasta 1913 el territorio contó con solo un facultativo, encargado de realizar tanto la tarea médica como sanitaria y preventiva oficial. Los médicos que llegaban al territorio se dedicaban a la actividad privada y su relación con las instituciones públicas era esporádica.

A principios del siglo XX, según un informe de José Oliver, médico oficial y luego director de la Asistencia Pública, se indicaba que el mayor centro urbano de La Pampa, de cuatro mil habitantes (Santa Rosa), contaba con solo un hospital a cargo de la Sociedad de Beneficencia con treinta camas (Di Liscia, 2008). Ese nosocomio brindaba asistencia también a la campaña y alrededores. Se describía un panorama completo de las ordenanzas respecto a salubridad urbana (agua y cloacas, basuras, limpieza de calles, ubicación e higiene de mataderos, cementerios y prostíbulos) de otras localidades, donde reinaba el más completo abandono de la higiene; muchos pueblos, sobre todo en el oeste, carecían de médicos. El atraso se encarnaba en la figura de los curanderos y en la imposibilidad de combatirlos con las armas de la modernidad: la eficacia médica, por un lado, y la legislación, por el otro.

En 1904, por insistencia de los higienistas Emilio Coni y José Penna, se reglamentó la ley de obligatoriedad de la vacunación antivariólica en todo el territorio nacional y en 1909 se estableció la declaración obligatoria de enfermedades infecciosas (tuberculosis, difteria, viruela, peste, fiebre amarilla y otras) en las "oficinas sanitarias", ubicadas en cada capital. En dichas oficinas se efectuaría la vacunación de la capital mientras que en la campaña se habilitaba a guardias sanitarios, que recibían el apoyo de los maestros en las escuelas, para recorrer y brindar los servicios de inmunización al resto de la población. Entre 1904 a 1911, totalizan a 13.439 habitantes inmunizados por primera o segunda vez por los tres guardias vacunadores (Di Liscia, 2007).

En 1913, se creó en Santa Rosa la Asistencia Pública, dependiente del Departamento Nacional de Higiene bajo la dirección de Penna. Una de sus principales funciones fue extender la vacunación antivariólica, puesto que había frecuentes epidemias y esta política generalizada es casi la única que recibió atención a nivel general (Di Liscia, 2011).

La vacunación requería esfuerzo y recursos, además de la colaboración de las familias y la anuencia de los adultos, muchos de los cuales se vacunaban por primera vez con sus hijos. Sabemos también que hubo resistencia y, frente a ella, estuvieron codo a codo tanto educadores como policías. El Consejo Nacional de Educación, una institución también general, promovió desde finales del siglo XIX la cultura higiénica. Las maestras - puesto que esta profesión era claramente femenina - pregonaban tanto las ventajas de la higiene como de la vacunación y a la llegada del vacunador actuaban como intermediarias para convencer a los renuentes. Las fuerzas policiales acompañaban también a los vacunadores ya que no siempre era posible la persuasión y la legislación implicaba sanciones.

Desde 1913 la vacunación quedó a cargo de la Asistencia Pública, que también vacunó en cárceles y escuelas y envió delegaciones al oeste del territorio con considerable esfuerzo tanto de recursos humanos como de presupuesto. La Pampa se libró de la viruela a finales de los 
años 1920, logrando con esfuerzo considerable la total inmunización de una población que era, por entonces, predominantemente rural. Otras prácticas hoy utilizadas para prevenir el contagio, como el aislamiento y confinamiento, no eran posibles ni tampoco adecuadas frente a la posibilidad real de generar la universalidad de la medida.

Si bien las epidemias no dejaron de preocupar ya que aparecieron enfermedades igualmente peligrosas (la difteria en la población infantil), otras cuestiones tanto o más graves, empezaron a incidir en el territorio. A mediados de los años 1930 se produce en La Pampa un despoblamiento a causa de una crisis ecológica y económica. La desocupación y la pobreza hicieron emerger, de acuerdo a las autoridades y sectores dirigentes, a ese núcleo "invisible" de las grandes ciudades que requería no solo vacunas sino políticas estructurales y preventivas de atención social y sanitaria. Ese tema merece otro relato.

Volvamos a la actual pandemia de covid-19, a casi un siglo de estas narraciones. En 2010, el total de habitantes en Argentina era 40.117.096 millones de habitantes, y en La Pampa, 318.951, distribuidos sobre todo en dos ciudades, Santa Rosa y General Pico (Censo Nacional..., 2010). En septiembre 2020 y frente al aumento de contagios y defunciones en toda Argentina (respectivamente, más de quinientos mil y 12 mil personas), en esta provincia mediterránea las fuentes oficiales citan sólo un total de 232 casos acumulados desde marzo, con tres víctimas fatales y 186 pacientes dados de alta (incidencia: 67,8/100 mil habitantes). Se enumera también disponibilidad de recursos críticos (camas de terapia intensiva y respiradores), que rondan un total de 91 y 84 respectivamente (Dirección de Epidemiología..., 2020). La noticia preocupante es la aceleración del tiempo de duplicación de casos (de ochenta a 28 días), por lo cual la epidemia, en el momento en que escribo estas palabras, aún no parece estar controlada. A pesar de una larga cuarentena y de controles exhaustivos para impedir ingreso de posibles personas contagiadas, sin actividades sociales ni educativas, con limitación regulada de las económicas y cierre (literal) de las "fronteras" internas, el virus manifestó ya circulación comunitaria y es posible que aún falte tiempo para volver a la "nueva normalidad" post-pandemia. Se inició en enero de 2021 la vacunación del personal de salud y los grupos de riesgo, pero restan aún muchos por ser inmunizados. En esto La Pampa no deja de parecerse al resto de Argentina, y en realidad, de gran parte de nuestro planeta.

\section{NOTA}

${ }^{1}$ El siguiente texto es una versión más completa, actualizada y sometida a revisión de pares de un post que apareció en el blog de História, Ciências, Saúde - Manguinhos.

\section{REFERENCIAS}

CENSO NACIONAL de Poblacion, Hogares Y Viviendas, Instituto Nacional de Estadísticas y Censos, Buenos Aires, 2010. Disponible en: https://www.indec.gob.ar/indec/web/Nivel4CensoNacional-999-999-Censo-2010. Acceso en: 17 sep. 2020.
DI LISCIA, María Silvia. Marcados en la piel. Vacunación y viruela en Argentina (1870-1910). Cadernos de Saúde Pública, v.16, n.2, p.409-422, 2011.

DI LISCIA, María Silvia. Imaginarios y derroteros de la salud en el interior argentino. 
Los Territorios Nacionales (fines del XIX y principios del XX), Entrepasados: Revista de Historia, n.33, p.49-69, 2008.

DI LISCIA, María Silvia. Instituciones, médicos y sociedad. Las posibilidades y los problemas en el territorio pampeano (1884-1933). In: Di Liscia, María Silvia; Lluchu, Andrea; Lassalle, Ana María (ed.). Al oeste del paraíso: la transformación del espacio natural, económico y social en la Pampa
Central (siglos XIX-XX). Buenos Aires: Miño y Dávila-Edulpam, 2007. p.123-154.

DIRECCIÓN DE EPIDEMIOLOGÍA, Ministerio de Salud, Provincia de La Pampa, 2020. Disponible en: https://salud.lapampa.gob.ar/mds/files/ vigilancia/SALA\%20DE\%20SITUACION\%20 COVID-19.\%20LA\%20PAMPA_08_09_2020.pdf. Acceso en: 17 sep. 2020.

\section{$\rightarrow \rightarrow \rightarrow<<$}

